\title{
CHEMICAL EFFECTS OF LANTHANIDES AND ACTINIDES IN GLASSES DETERMINED WITH ELECTRON ENERGY LOSS SPECTROSCOPY
}

RECEIVED

JUL 181996

OSTI

Jeffrey A. Fortner, Edgar C. Buck, Adam J. G. Ellison, and John K. Bates

ARGONNE NATIONAL LABORATORY

Chemical Technology Division

9700 South Cass Avenue

Argonne, IL 60439-4837

The submifted manuscript has been
authored by a contractor of the U.S.
Government under contract No. W-31-108-
ENG-38. Accordingly, the U.S. Government
retains a nonexclusive, royalty-free license
to publish or reproduce the published form of
this contribution, or allow others to do so, for
U.S. Government purposes.

Prepared for Presentation at

30th Annual Meeting of Microbeam Analysis Society

August 11-15, 1996

Minneapolis, Minnesota

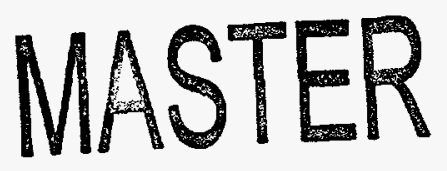

This work supported by the U.S. Department of Energy, Office of Environmental Management, under contract W-31-109-ENG-38. 


\title{
CHEMICAL EFFECTS OF LANTHANIDES AND ACTINIDES IN GLASSES DETERMINED WITH ELECTRON ENERGY LOSS SPECTROSCOPY
}

\author{
Jeffrey A. Fortner, Edgar C. Buck, Adam J. G. Ellison, and John K. Bates \\ Chemical Technology Division, Argonne National Laboratory, Argonne, IL 60439, USA.
}

The chemical and structural environments of $f$-electron elements in glasses are the origin of many of the important optical, electronic, and magnetic properties of materials incorporating these elements. Thus, the oxidation state and chemical coordination of lanthanides and actinides in host materials is an important design consideration in optically active glasses, magnetic materials, perovskite superconductors, and nuclear waste materials.

The energy loss spectra of the lanthanides are characterized by sharp $3 d_{3 / 2} \rightarrow 4 f_{5 / 2}\left(\mathrm{M}_{4}\right)$ and $3 d_{5 / 2} \rightarrow$ $4 f 7_{n}\left(M_{5}\right)$ lines, the relative intensities of which are determined by the $4 f$-shell occupancy of the excited ion. For the light lanthanides, the dependence of these relative peak heights on $4 f$-shell occupancy is quite pronounced. In particular, the ratio of the $\mathrm{M}_{4}$ to $\mathrm{M}_{5}$ peak areas in the second derivative spectra is extremely sensitive to the formal valence of the multivalent elements $\mathrm{Ce}$ and $\mathrm{Pr}$. In figure 1, the EELS spectra are presented for $\mathrm{Ce}(\mathrm{III})$ and $\mathrm{Ce}$ (IV) in well-characterized reference materials. The ratio of the $\mathrm{M}_{4} / \mathrm{M}_{5}$ lines calculated by various methods is plotted against $f$-shell occupancy in figure 2 . The present second derivative data are plotted along with those of Manoubi $e t$ al. [1], who fit their experimental peaks from lanthanide oxides with Lorentzian functions, and also the theoretical multiplet calculations of Thole et al. [2] ( $\mathrm{A}_{3 / 2}$ and $\mathrm{A}_{5 / 2}$ used instead of $\mathrm{M}_{4}$ and $\mathrm{M}_{5}$, respectively). The systematic divergence of the second derivative data from the Lorentzian fits and theoretical peak areas occurs because the $\mathrm{M}_{4}$ line is broader than the $\mathrm{M}_{5}$ line, which reduces its relative intensity in the second derivative accordingly.

We have made use of the characteristic line shapes of cerium to determine its oxidation state in alkali borosilicate glasses that are being developed for immobilization of plutonium. Cerium, it should be noted, is often used as a "surrogate" element for plutonium in materials design because of its similar ionic size (for $\mathrm{Pu}$ in the +3 and +4 states) and preferred chemical coordination. The solubility of the plutonium (or cerium) in a waste glass will likely be determined by its redox state in the glass. By examining several prototype glass compositions with EELS (figure 3), it was found that the redox state of cerium doped to $7 \mathrm{wt} \%$ could be varied by suitable choice of alkali elements in the glass formula.

By analogy with the lanthanides, the intensity ratio of the $\mathrm{N}_{4}$ and $\mathrm{N}_{5}$ lines in actinide elements, which correspond to $4 d_{3 / 2} \rightarrow 5 f_{5 / 2}$ and $4 d_{5 / 2} \rightarrow 5 f_{7 / 2}$ transitions, respectively, might be expected to decrease as occupancy of the $5 f$ orbitals increases. For example, by this argument, the uranyl ion should display a $\mathrm{N}_{4} / \mathrm{N}_{5}$ ratio close to 1.0 ; instead, the ratio is smaller. In actinides, the relativistic contraction leads to strong hybridization of $5 f$ orbits with the $6 d$ and $7 s$ orbitals. This relativistic contraction is around $2 \%$ for the lanthanides but at least $30 \%$ for the actinides. Excitation will occur to these $6 d$ and $7 s$ levels and will complicate the edge shape. Thus, we cannot assume that the same correlation of $\mathrm{N}_{4} / \mathrm{N}_{5}$ intensity ratios with $f$-orbital occupancy that is seen for the lanthanides will be observed in the actinides. Instead, it is probable that crystal field effects will determine the spectral shape for the actinides. In glasses, however, the flexible local structure may lead to coupling between the oxidation state and crystal field effects, allowing a straightforward interpretation. Preliminary EELS results on a plutonium-doped glass appear in figure 4, illustrating the small actinide $\mathrm{N}_{4} / \mathrm{N}_{5}$ ratio. This figure also shows that the $\mathrm{Pu}-\mathrm{N}_{4,5}$ white line cross section is comparable to that of gadolinium $\mathrm{M}_{4.5}$ [3]. 


\section{REFERENCES}

1. T. Manoubi, C. Colliex, and P. Rez, J. Elect. Spec. and Related Phen. 50, 1 (1990).

2. B. T. Thole, G. van der Laan, J. C. Fuggle, G. A. Sawatzky, R. C. Karnatak, and J.-M. Esteva, Phys. Rev. B 32 (8), 5107 (1985).

3. This work supported by the U. S. Department of Energy, under contract W-31-109-ENG-38.

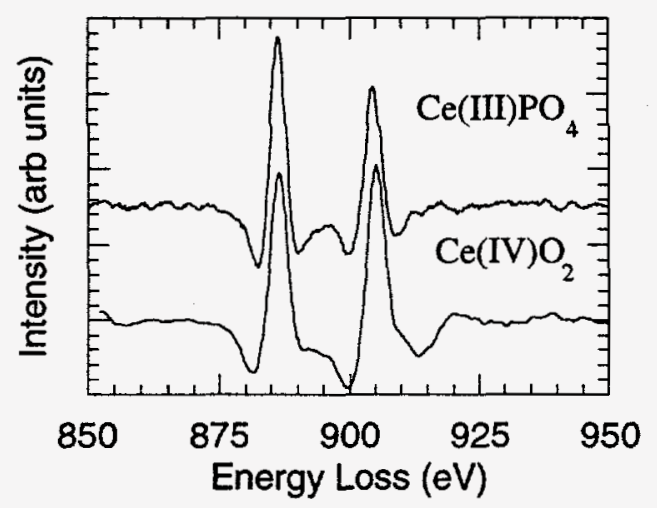

Figure 1. Second derivative EELS spectra of cerium (IV) oxide and cerium(III) orthophosphate. Note the dramatic change in the ratio of the $\mathrm{M}_{4}(903 \mathrm{eV})$ to $\mathrm{M}_{5}(886 \mathrm{eV})$ lines.

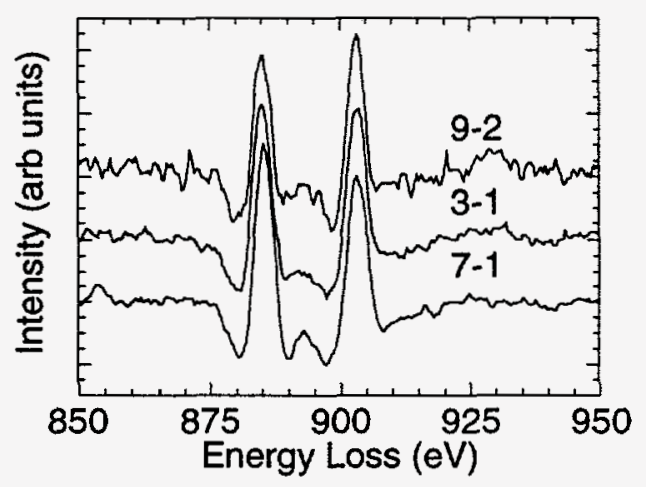

Figure 3. Second derivative EELS spectra of cerium $\mathbf{M}_{4.5}$ edges in prototype glasses designed for plutonium disposition. The formal valence of the cerium varies from 3.4 ("7-1") to 4 ("9-2") as a function of the relative proportions of $\mathrm{K}$ and $\mathrm{Li}$ in the glasses.
- +3 ion $\diamond+4$ ion $\circ M_{4} M_{5}$, fits (ref. 1)

++3 ion $A_{3 / 2} / A_{5 / 2}$, calculated (ref. 2)

$x+4$ ion, $A_{3 / 2} / A_{5 / 2}$, calculated (ref. 2)

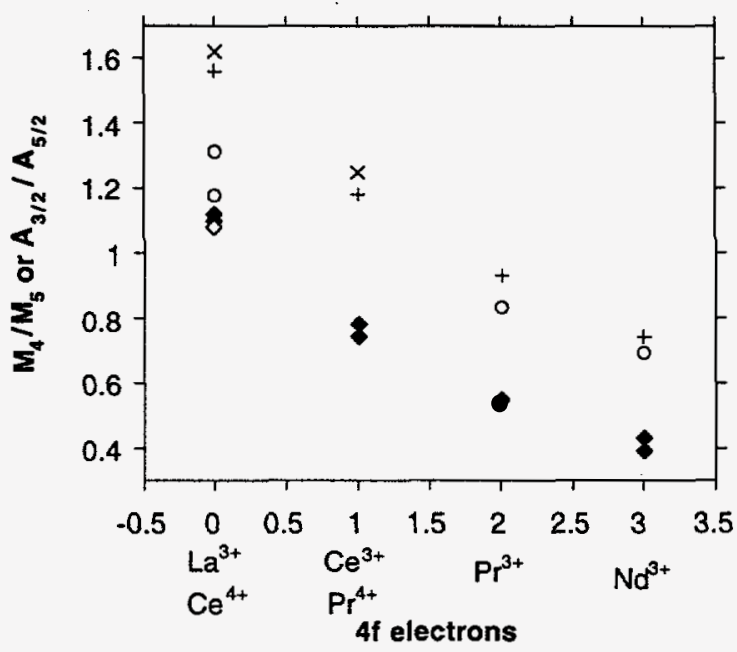

Figure 2. Dependence of the $M_{4} / M_{5}$ spin-orbit group ratio on the occupancy of the $4 f$ level for the light lanthanides.

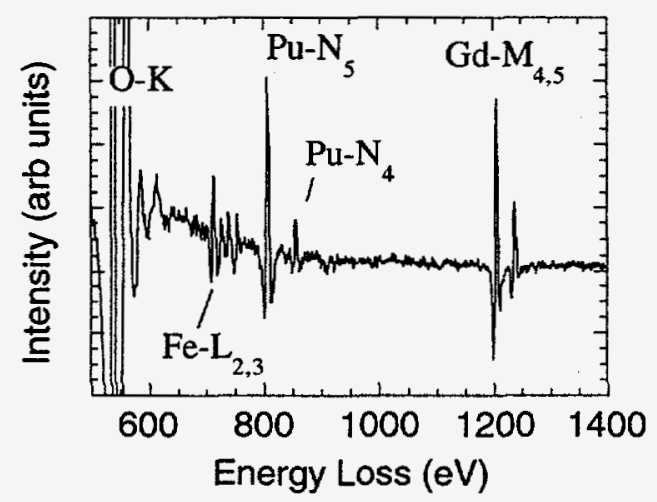

Figure 4. Plutonium $\mathrm{N}$-edges in a glass doped to 7 wt \% Pu. Gadolinium is a neutron poison present in a 1:1 ratio with the plutonium, providing a relative measure of the plutonium $\mathrm{N}$-edge cross sections. 


\section{DISCLAMMER}

This report was prepared as an account of work sponsored by an agency of the United States Government. Neither the United States Government nor any agency thereof, nor any of their employees, makes any warranty, express or implied, or assumes any legal liability or responsibility for the accuracy, completeness, or usefulness of any information, apparatus, product, or process disclosed, or represents that its use would not infringe privately owned rights. Reference herein to any specific commercial product, process, or service by trade name, trademark, manufacturer, or otherwise does not necessarily constitute or imply its endorsement, recommendation, or favoring by the United States Government or any agency thereof. The views and opinions of authors expressed herein do not necessarily state or reflect those of the United States Government or any agency thereof. 